\title{
Atorvastatin enhances neurite outgrowth in cortical neurons in vitro via up-regulating the Akt/mTOR and Akt/GSK-3 $\beta$ signaling pathways
}

\author{
Ying JIN*, Hai-juan SUI, Yan DONG, Qi DING, Wen-hui QU, Sheng-xue YU, Ying-xin JIN \\ Department of Pharmacology, Liaoning Medical University, Jinzhou 121001, China
}

\begin{abstract}
Aim: To investigate whether atorvastatin can promote formation of neurites in cultured cortical neurons and the signaling mechanisms responsible for this effect.

Methods: Cultured rat cerebral cortical neurons were incubated with atorvastatin $(0.05-10 \mu \mathrm{mol} / \mathrm{L})$ for various lengths of time. For pharmacological experiments, inhibitors were added $30 \mathrm{~min}$ prior to addition of atorvastatin. Control cultures received a similar amount of DMSO. Following the treatment period, phase-contrast digital images were taken. Digital images of neurons were analyzed for total neurite branch length (TNBL), neurite number, terminal branch number, and soma area by SPOT Advanced Imaging software. After incubation with atorvastatin for $48 \mathrm{~h}$, the levels of phosphorylated 3-phosphoinoside-dependent protein kinase-1 (PDK1), phospho-Akt, phosphorylated mammalian target of rapamycin (mTOR), phosphorylated 4E-binding protein 1 (4E-BP1), p70S6 kinase

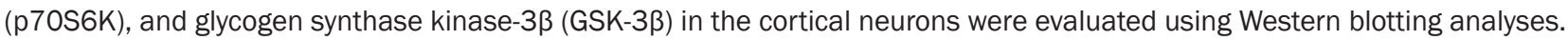
Results: Atorvastatin (0.05-10 $\mu \mathrm{mol} / \mathrm{L})$ resulted in dose-dependent increase in neurite number and length in these neurons. Pretreatment of the cortical neurons with phosphatidylinositol 3-kinase (PI3K) inhibitors LY294002 (30 $\mu \mathrm{mol} / \mathrm{L})$ and wortmannin ( $5 \mu \mathrm{mol} / \mathrm{L})$, Akt inhibitor tricribine $(1 \mu \mathrm{mol} / \mathrm{L})$ or mTOR inhibitor rapamycin $(100 \mathrm{nmol} / \mathrm{L})$ blocked the atorvastatin-induced increase in neurite outgrowth, suggesting that atorvastatin promoted neurite outgrowth via activating the PI3K/Akt/mTOR signaling pathway. Atorvastatin $(10 \mu \mathrm{mol} / \mathrm{L})$ significantly increased the levels of phosphorylated PDK1, Akt and mTOR in the cortical neurons, which were prevented by LY294002 (30 $\mu \mathrm{mol} / \mathrm{L})$. Moreover, atorvastatin $(10 \mu \mathrm{mol} / \mathrm{L})$ stimulated the phosphorylation of $4 \mathrm{E}-\mathrm{BP} 1$ and $\mathrm{p} 70 \mathrm{~S} 6 \mathrm{~K}$, the substrates of mTOR, in the cortical neurons. In addition, atorvastatin ( $10 \mu \mathrm{mol} / \mathrm{L})$ significantly increased the phosphorylated GSK-3 $\beta$ level in the cortical neurons, which was prevented by both LY294002 and tricribine.

Conclusion: These results suggest that activation of both the PI3K/Akt/mTOR and Akt/GSK-3ß signaling pathways is responsible for the atorvastatin-induced neurite outgrowth in cultured cortical neurons.
\end{abstract}

Keywords: statin; atorvastatin; cortical neurons; neuritogenesis; PI3-kinase; GSK-3 $\beta$

Acta Pharmacologica Sinica (2012) 33: 861-872; doi: 10.1038/aps.2012.59; published online 18 Jun 2012

\section{Introduction}

Neurons form functional networks by extending axons and dendrites (collectively termed neurites) that can connect via synapses to other neurons and cells. Molecules that promote effective neurite growth may have therapeutic potential in the treatment of a wide variety of disorders of the human nervous system. The statins are important cholesterol lowering agents for patients at risk of cardiovascular disease. However, many studies show that statins may have additional neuroprotective properties independent of their effect on cholesterol synthesis. Statins can reduce the region of focal cerebral ischemia ${ }^{[1]}$

\footnotetext{
* To whom correspondence should be addressed.

E-mail jyjinying@yahoo.com.cn

Received 2011-10-05 Accepted 2012-04-28
}

and protect cortical neurons from excitotoxity ${ }^{[2]}$. Recent studies reported that statins can preventively and therapeutically attenuate traumatic brain injury and spinal cord injury. These beneficial effects of statins include upregulation of brainderived neurotrophin factor (BDNF) and vascular endothelial growth factor (VEGF) and activation of the Akt-mediated signaling pathways ${ }^{[3-5]}$. Epidemiological studies have established a link between the use of statins and a lowered risk of developing Alzheimer's disease (AD) ${ }^{[6]}$. While it is unclear exactly how statin treatment leads to a reduction in risk, there is significant evidence to suggest that statins affect amyloid precursor protein (APP) processing and consequently reduce plaque formation ${ }^{[7-10]}$. In addition, the treatment of cells in culture with statins induces a number of striking morphological changes. For example, statin treatment has been reported to 
promote neurite outgrowth ${ }^{[11-14]}$. Furthermore, enhancement of neurite outgrowth by statins treatment is probably mediated by inhibition of Rho isoprenylation, a cholesterol-independent mechanism $^{[12]}$. In addition to the Rho family of proteins, the serine/threonine kinase Akt, also known as protein kinase B, has also been revealed as a key mediator of several aspects of neurite outgrowth. Akt is the major effector of the phosphatidylinositol 3-kinase (PI3K) signaling pathway. Downstream of Akt, several substrates have been identified that are likely to play key roles in Akt-mediated neurite outgrowth, such as mammalian target of rapamycin (mTOR) and glycogen synthase kinase $3 \beta$ (GSK-3 $\beta)^{[15]}$. mTOR is a serine/threonine protein kinase that regulates multiple cellular functions including neurite outgrowth. PI3K/Akt/mTOR signaling has been shown to promote growth and branching in hippocampal neurons $^{[16]}$. The serine/threonine protein kinase GSK-3 $\beta$ is a key substrate. Activated Akt phosphorylates at GSK-3 $\beta$ at Ser-9 to inactivate its kinase activity ${ }^{[17]}$. It has been reported that statins can induce the phosphorylation of $\mathrm{Akt}^{[3,18,19]}$. These observations suggest the possibility that statins can affect neurite outgrowth by activation of the Akt signaling pathway. In the present study, we examine the effects of the widely employed hydrophilic statin atorvastatin on neurite growth in primary cultured cortical neurons and investigate in more detail the major signaling pathways that mediate these effects. Our data demonstrate that atorvastatin promotes neurite outgrowth. The mechanism mediating this effect involves the PI3K/Akt/ mTOR and PI3K/Akt/GSK-3 $\beta$ signaling pathways.

\section{Materials and methods}

Atorvastatin was obtained from LKT Laboratories, Inc (St Paul, MN, USA). LY294002 and wortmannin (PI3K inhibition), LY303511 (inactive analogue of LY294002), PD98059 and U0126 (MEK inhibition), and rapamycin (mTOR inhibition) were from Calbiochem (Darmstadt, Germany). SB415286 (GSK3 $\beta$ inhibition) and triciribine (TCBN; Akt inhibition) were from Santa Cruz Biotechnology, Inc (Santa Cruz, CA, USA).

\section{Primary cortical neuron cultures}

Primary cultures were obtained from the cerebral cortex of 0to 24-h-old Sprague-Dawley rats. After removal of the meninges and white matter, the cerebral cortex was collected in Hanks' solution without $\mathrm{Ca}^{2+}$ and $\mathrm{Mg}^{2+}$ (D-Hanks). The cortex was then mechanically fragmented, transferred to D-Hanks' solution containing $0.125 \%$ trypsin, and incubated for $15 \mathrm{~min}$ at $37^{\circ} \mathrm{C}$. Following trypsinization, cells were washed twice with DMEM and re-suspended in DMEM/F12 medium containing $10 \%$ heat-inactivated fetal bovine serum, $10 \%$ horse serum, glutamine $(3 \mathrm{mg} / \mathrm{mL})$, insulin $(0.25 \mathrm{mg} / \mathrm{mL})$, penicillin $(50 \mathrm{U} / \mathrm{mL})$, and streptomycin $(50 \mathrm{mg} / \mathrm{mL})$. The cells were then plated onto $35-\mathrm{mm}$ cell culture dishes $\left(\sim 150\right.$ cells $\left./ \mathrm{mm}^{2}\right)$ or 6-well culture plates pre-coated with poly-L-lysine $(0.1 \mathrm{~g} / \mathrm{L}$, Sigma, St Louis, MO, USA) and kept at $37^{\circ} \mathrm{C}$ in a humidified atmosphere of $5 \% \mathrm{CO}_{2} / 95 \% \mathrm{O}_{2}$. Forty-eight hours after plating, the media were removed and replaced with DMEM containing glutamine $(3 \mathrm{mg} / \mathrm{mL}), \mathrm{B}-27$ ( $2 \%$; Life Technolo- gies, Gaithersburg, MD, USA) and cytosine arabinofuranoside (final concentration $5 \mu \mathrm{mol} / \mathrm{L}$, Sigma) to inhibit the proliferation of non-neuronal cells. After $4 \mathrm{~d}$ in culture, the cells were incubated for various lengths of time in media containing atorvastatin $(0.05-10 \mu \mathrm{mol} / \mathrm{L})$. For pharmacological experiments, inhibitors were added $30 \mathrm{~min}$ prior to addition of atorvastatin. Control cultures received a similar amount of DMSO, which was the organic solvent for all inhibitors. Microtubule-associated protein immunostaining indicated that about $90 \%$ of the cells were neurons after arabinofuranoside treatment for $3 \mathrm{~d}$.

\section{Immunofluorescence for MAP-2}

To examine the effect of treatment on neurite outgrowth, neurons were incubated with media containing the appropriate test compound for an appropriate period of time. Following the treatment period, neurons were fixed with $4 \%$ paraformaldehyde/PBS at room temperature for $30 \mathrm{~min}$ and permeabilized in $0.2 \%$ Triton X-100/PBS for 5 min. Following washes with PBS, the neurons were incubated for $1 \mathrm{~h}$ in blocking solution (TBS containing 5\% BSA at room temperature). Mouse monoclonal anti MAP-2 antibody (1:500, Abcam Inc, Cambridge, MA, USA) diluted in the blocking buffer was applied and incubated overnight at $4^{\circ} \mathrm{C}$. After extensive washes, Cy3conjugated anti-mouse secondary antibody (Life Technologies, Gaithersburg, MD, USA) was applied and incubated at $37^{\circ} \mathrm{C}$ for $1 \mathrm{~h}$.

\section{Neuronal imaging and analysis}

Neuronal morphology was analyzed using an Olympus CKX41SF microscope, a Universal Imaging SPOT CCD camera and the SPOT Advanced Imaging software. Briefly, images of neurons were analyzed for total neurite branch length (TNBL), neurite number, terminal branch number, and soma area. TNBL and soma area were calculated using image measuring software, whereas neurite number and terminal branch number were counted manually. Five to six fields per well were chosen at random and only neurons distinguishable from neighboring neurons were evaluated to ensure the precision of the measurements; approximately 50-60 neurons were quantified per treatment group per experiment. The experimental group was kept blind until all analysis was done, and then the data from the same group of experiments were pooled together. Each experiment was performed in triplicate, unless otherwise noted.

\section{Western blot analyses}

Cells treated with atorvastatin or inhibitor described above were lysed in RIPA Lysis Buffer [Beyotime Institute of Biotechnology; $50 \mathrm{mmol} / \mathrm{L}$ Tris ( $\mathrm{pH} 7.4$ ), $150 \mathrm{mmol} / \mathrm{L} \mathrm{NaCl}$, $1 \%$ Triton $\mathrm{X}-100,1 \%$ sodium deoxycholate, $0.1 \%$ SDS, 1 $\mathrm{mmol} / \mathrm{L}$ sodium orthovanadate, $10 \mathrm{mmol} / \mathrm{L}$ sodium fluoride, $1 \mathrm{mmol} / \mathrm{L}$ phenylmethylsulphonyl fluoride, and $1 \times$ Halt protease inhibitor cocktail], after which detergent-insoluble materials were removed by centrifugation at $12000 \times g$ for 10 min. Protein concentration in the soluble fraction was measured using an Enhanced BCA protein assay kit (Beyotime 
Institute of Biotechnology, Haimen, China). Equal amounts of protein were then separated by SDS-PAGE, transferred onto nitrocellulose membranes, and probed with primary antibodies against the following proteins: rabbit anti-phospho-PDK1 (Ser241), rabbit anti-PDK1, rabbit anti-phospho-Akt (Ser473), rabbit anti-Akt, rabbit anti-phospho-PTEN (Ser380) (phosphatase and tensin homolog deleted on chromosome 10), rabbit anti-PTEN, rabbit anti-phospho-mTOR (Ser2448), rabbit anti-mTOR, rabbit anti-phospho-p70S6K (Thr389), rabbit antip70S6K, rabbit anti-phospho-4EBP1 (Thr37/46), anti-4EBP1, rabbit anti-phospho-GSK-3 $\beta$ (Ser9), and anti-GSK-3 $\beta$ (all from Cell Signaling Technology, Beverly, MA, USA and diluted 1:1000). Bound antibodies were detected with horseradish peroxidase-conjugated anti-rabbit immunoglobulin G (IgG) (Cell Signaling Technology) each diluted 1:2000 and Supersignal West Pico chemiluminescense substrate (Pierce, Rockford, IL, USA). Staining intensity was quantified from four blots derived from four independent experimental trials. The density of each band was quantified with Image J software and normalized to total kinase or $\beta$-actin expression. The protein levels reported in the figures were obtained as a ratio between the band intensity for the protein of interest and the band intensity of total kinases or $\beta$-actin (Sigma), used as loading control.

\section{Statistical analysis}

Statistical analyses were conducted using multifactor ANOVA including appropriate variables or $t$-test when suitable. Values represent mean \pm SEM. $P$ values $<0.05$ were considered statistically significant.

\section{Results}

Atorvastatin increases neurite outgrowth and soma size in cortical neurons

To test the effects of atorvastatin on neurite outgrowth, we used dissociated postnatal cortical neuronal cultures as our model system. The initial set of experiments was designed to investigate whether atorvastatin affects neurite outgrowth in cultured cortical neurons. Atorvastatin $(0.05-10 \mu \mathrm{mol} / \mathrm{L})$ was added to cultures of cortical neurons at $4 \mathrm{DIV}$, at a stage in which neurites mature by elongating and branching. TNBL, neurite number, terminal branch number, and soma area were measured after an additional $48 \mathrm{~h}$. As shown in Figure 1 , incubation of cortical neurons with atorvastatin (0.05-10 $\mu \mathrm{mol} / \mathrm{L})$ for $48 \mathrm{~h}$ resulted in a dose-dependent increase in the soma size. Both the neurite number and terminal branch number were significantly increased, resulting in a net increase of TNBL. The maximum dose of atorvastatin was $10 \mu \mathrm{mol} / \mathrm{L}$ for neurite outgrowth. Therefore, we chose this treatment protocol to identify the underlying mechanisms of this event in all subsequent experiments. In our culture of cortical neurons, cells were classified as pyramidal or nonpyramidal on the basis of morphological features. However, there was no difference in the effect of atorvastatin on pyramidal and nonpyramidal neurons. In a time course analysis, increased TNBL and terminal branch number were detected as early as $12 \mathrm{~h}$ after atorvastatin treatment (Figure 2A and 2B). A significant increase in neurite number was detected at $24 \mathrm{~h}$ after atorvastatin treatment (Figure 2C). A significant increase in soma area was detected at $48 \mathrm{~h}$ after atorvastatin treatment (Figure 2D).

\section{Atorvastatin promotes neurite outgrowth via the PI3K-Akt pathway in cortical neurons}

Having established that atorvastatin treatment stimulated neurite outgrowth, we next sought to determine the specific signaling pathways that contribute to these effects. At first, we focused on the PI3K-Akt and MEK-MAPK signaling pathways which have recently been shown to be important for the control of neurite outgrowth. In addition, statins are reported to activate the PI3K pathway, resulting in the phosphorylation of $\mathrm{Akt}^{[20]}$ in endothelial cells. Therefore, the requirement for PI3K activation was first examined. Pretreatment of the cortical neurons with the specific PI3K inhibitor LY294002 (30 $\mu \mathrm{mol} / \mathrm{L})$ significantly blocked atorvastatin-induced neurite outgrowth as reflected by neurite number, terminal branch number and soma area (Figure 3). Similar results were also observed with the use of another structurally unrelated PI3K inhibitor, wortmannin $(5 \mu \mathrm{mol} / \mathrm{L})$ (data not shown). In contrast the inactive analogue of LY294002, LY303511 (20 $\mu \mathrm{mol} / \mathrm{L})$ did not affect the effect of atrovastatin (data not shown). These results show that the activation of PI3K is required for atorvastatininduced increases in neurite outgrowth in cultured cortical neurons. Pretreatment of the cortical neurons with the specific MEK inhibitor U0126 (10 $\mu \mathrm{mol} / \mathrm{L})$ also partly blocked the atorvastatin-induced increase in TNBL, terminal branch number, and neurite number. PD98059 (30 $\mu \mathrm{mol} / \mathrm{L}$; MEK inhibitor) showed similar results. Remarkably, the atorvastatininduced increase in soma area was blocked by LY294002 but not by U0126 (Figure 3E). Concurrent application of LY294002 and U0126 to block both the PI3K and MAPK signaling pathways completely blocked atorvastatin-induced increases in neurite outgrowth. Interestingly, neither LY294002 nor U0126 changed any of the neurite parameters in control neurons (Figure 3). Together, the data reported above indicate that atorvastatin promotes neurite outgrowth and branching through both the PI3K/Akt and MAPK pathways, whereas atorvastatin increases soma area through only the PI3K/Akt pathway.

Pretreatment of the cortical neurons with tricribine, which blocks all Akt isoforms (Akt1, Akt2, and Akt3) without inhibiting known upstream activators PDK1 and PI3K, completely eliminated the effects of atorvastatin on TNBL, terminal branch number, neurite number, and soma size. Interestingly, tricribine alone also reduced soma size in control neurons (Figure 3).

To further ascertain the requirement for the activation of the PI3K/Akt signaling pathway in the atorvastatin-induced increases in neurite outgrowth, we used phospho-specific antibodies to measure the relative levels of phosphorylated, active forms of the protein kinases phosphoinositide-dependent kinase-1 (PDK1) and Akt after cultured neurons were treated with atorvastatin. For PDK1, we used an antibody specific for 

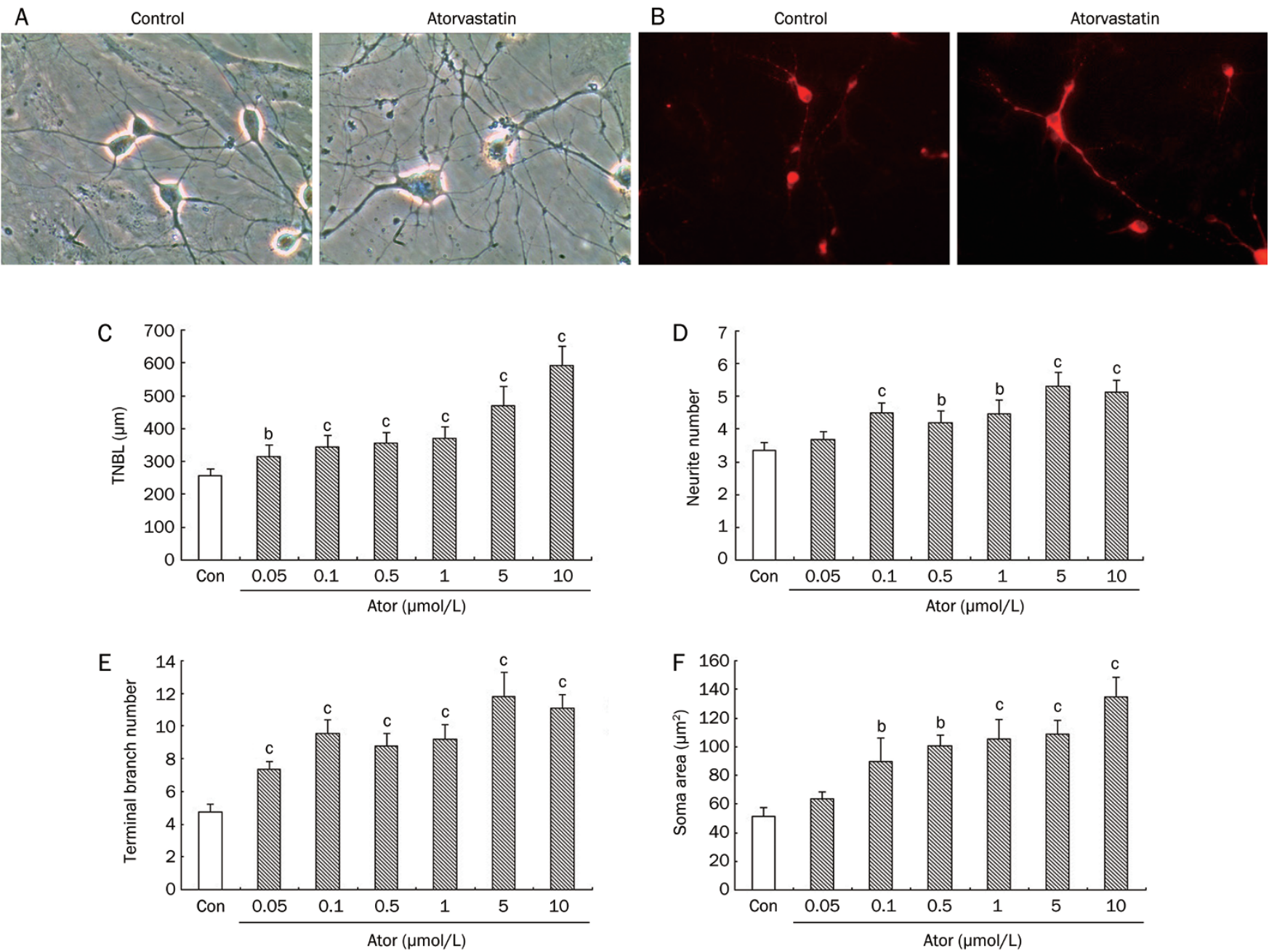

Figure 1. Atorvastatin (Ator) promotes neurite growth in rat cortical neurons in a dose-dependent manner. (A) Examples of neurons taken using phasecontrast microscopy depicting cortical neurons either in the absence (left panel) or presence of $10 \mu \mathrm{mol} / \mathrm{L}$ atorvastatin (right panel). (B) Dendritic structures are confirmed by immunostaining for the dendritic marker MAP-2. Cultured cortical cells were treated at 4 DIV either with vehicle solution (Control, $0.1 \% \mathrm{DMSO}$ ) or with $10 \mu \mathrm{mol} / \mathrm{L}$ atorvastatin for $48 \mathrm{~h}$. Following the treatment period, phase-contrast digital images of the cells were taken using a phase-contrast microscope. The graphs show mean \pm SEM for TNBL (C), neurite number (D), terminal branch number (E), and soma area (F). Data are from at least three independent experiments ( $n=50-60$ cells). ${ }^{b} P<0.05,{ }^{\circ} P<0.01$ demonstrates statistical significance by one-way ANOVA, followed by least significant difference (LSD)'s post-hoc test.

phosphorylated serine 241, which is on the activation loop of PDK1 and is essential for kinase activity. For Akt, we used antibody specific for phosphorylated serine 473 , which is necessary for maximal activation of $\mathrm{Akt}^{[21]}$. As expected, incubation of cultured cortical neurons at 4 DIV with atorvastatin $(0.1,1$, and $10 \mu \mathrm{mol} / \mathrm{L})$ for $48 \mathrm{~h}$ caused marked increases in phospho-PDK1 and phospho-Akt (Ser473) in a concentrationdependent manner without a concurrent increase in the total levels of PDK1 and Akt as measured on Western blots of lysates of neurons (Figure 4A). Next, to further confirm that the observed effect of atorvastatin on neurite outgrowth is mediated by elevated level of PIP3, we tested whether atorvastatin treatment can downregulate the PIP3 phosphatase PTEN, which is a negative regulator of the PI3K signaling pathway. The results showed that atorvastatin treatment did not affect the levels of phospho-PTEN (Ser380) expression (Figure 4A). In a time course analysis, increased phospho-PDK1 levels were detected as early as $6 \mathrm{~h}$ and leveled off between 48 to $96 \mathrm{~h}$ after atorvastatin treatment (Figure 4B). It is well documented that PDK1 is downstream of PI3K, therefore, we determined whether LY294002 $(30 \mu \mathrm{mol} / \mathrm{L})$ or wortmannin $(5 \mu \mathrm{mol} / \mathrm{L})$ could block the atorvastatin-induced increases in the phosphorylation of PDK1 and Akt. We found that LY294002 (30 $\mu \mathrm{mol} / \mathrm{L}$ ) significantly blocked the increases in PDK1 and Akt phosphorylation induced by atorvastatin. Similar results were also observed with the use of wortmannin $(5 \mu \mathrm{mol} / \mathrm{L})$ (data not shown). LY303511 (20 $\mu \mathrm{mol} / \mathrm{L})$ did not affect this action of atrovastatin. None of LY294002, wortmannin, or LY303511 alone altered the basal levels of phosphorylated PDK1 and Akt (Figure 4C and 4D). Neither PD98059 $(10 \mu \mathrm{mol} / \mathrm{L})$ nor U0126 

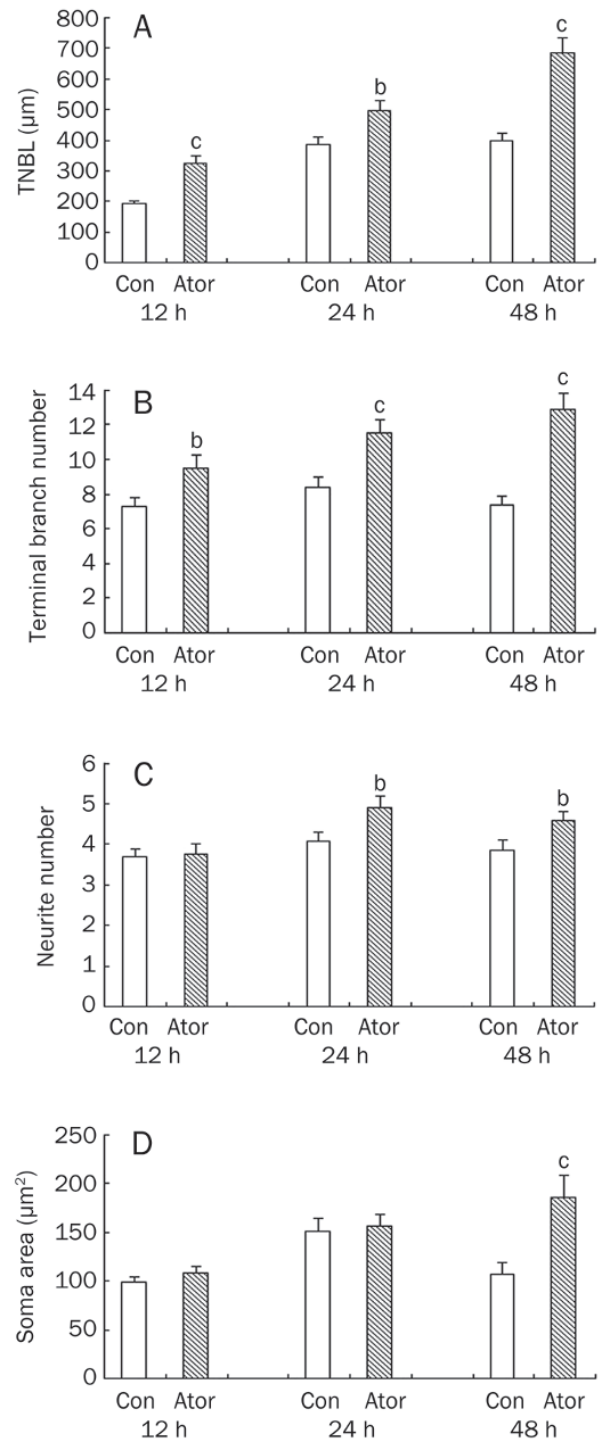

Figure 2. Atorvastatin $(10 \mu \mathrm{mol} / \mathrm{L})$ significantly enhanced neurite outgrowth after 12,24 , and $48 \mathrm{~h}$ of treatment. The graphs show mean \pm SEM for TNBL $(A)$, terminal branch number $(B)$, neurite number $(C)$, and soma area (D). Data are from at least three independent experiments ( $n=50-60$ cells). ${ }^{\mathrm{b}} P<0.05,{ }^{\mathrm{c}} P<0.01$ demonstrates statistical significance by one-way ANOVA, followed by least significant difference (LSD)'s posthoc test.

pretreatment blocked the action of atorvastatin on phosphorylated PDK1 and Akt (data not shown). Pretreatment of cortical neurons with tricribine $(1 \mu \mathrm{mol} / \mathrm{L})$ for 30 min completely blocked atorvastatin-induced increases in phospho-Akt levels. Tricribine $(1 \mu \mathrm{mol} / \mathrm{L})$ alone inhibited the basal levels of phosphorylated Akt (Figure 4D). Together, these results indicate that PI3K mediates the action of atorvastatin on PDK1 and Akt levels.

\section{Atorvastatin-induced neurite outgrowth is mTOR-dependent} mTOR is an important downstream node in the PI3K-Akt pathway. We next asked whether the increase in neurite outgrowth by atorvastatin occurs through an mTOR-coupled mechanism. We used rapamycin, a highly specific mTOR inhibitor, to further elucidate the downstream signaling mechanisms. This treatment decreased the phosphorylation of p70S6K on Thr389, which depends on mTOR activity ${ }^{[22]}$. As shown in Figure 5A-5E, pretreatment of cortical neurons with rapamycin (100 nmol/L) almost completely blocked atorvastatin-increased neurite outgrowth and soma size, indicating that a rapamycin-sensitive pathway is involved. We conclude therefore that atorvastatin stimulates neurite outgrowth in cultured cortical neurons in a rapamycin-sensitive manner.

To further ascertain the requirement for mTOR pathway activation in atorvastatin-induced neurite outgrowth, we used phospho-specific mTOR antibody (Ser2448), which has been shown to be important in the control of mTOR activity ${ }^{[23-25]}$, to measure the relative levels of phosphorylated, active forms of mTOR. As expected, atorvastatin $(10 \mu \mathrm{mol} / \mathrm{L})$ induced a significant increase in phosphorylated mTOR without a concurrent increase in the total level of this kinase (Figure $5 \mathrm{~F}$ ). Next, we tested the dependence of atorvastatin-induced mTOR phosphorylation on PI3K/Akt pathway. The results showed that LY294002 $(30 \mu \mathrm{mol} / \mathrm{L})$ and tricribine $(1 \mu \mathrm{mol} / \mathrm{L})$ completely blocked the atorvastatin-induced increase in phosphorylated mTOR (Figure 5F).

\section{Atorvastatin stimulates the phosphorylation of $\mathrm{p} 70 \mathrm{~S} 6 \mathrm{~K}$ and $4 \mathrm{E}$ - BP1}

mTOR stimulates translation by activating p70S6K, a kinase that increases synthesis of several components of the translation machinery ${ }^{[24]}$. The suppression of p70S6K impairs dendrite branching similarly to inhibition of $\operatorname{mTOR}^{[16,26]}$. We then asked if the atorvastatin-induced increases in neurite outgrowth are p70S6K-dependent by examining the phosphorylation state of p70S6K after atorvastatin treatment. We used an antibody specific for phosphorylated threonines 389, a site whose phosphorylation is vital for p70S6K activation ${ }^{[27]}$. When cultured cortical neurons were treated with atorvastatin $(10 \mu \mathrm{mol} / \mathrm{L})$ for $48 \mathrm{~h}$, the phosphorylation of p70S6K was significantly increased. Furthermore, the atorvastatininduced increases in the phosphorylation of p70S6K were completely blocked by LY294002 $(30 \mu \mathrm{mol} / \mathrm{L})$ and rapamycin (100 nmol/L) pretreatment, respectively (Figure 6A).

In addition, because activation of mTOR can also contribute to translational initiation by phosphorylation of $4 \mathrm{E}-$ binding protein 1 (4E-BP1), which binds to and represses the function of the cap-binding translation factor elF4E, we asked if this regulatory protein may have a role in atorvastatin-induced neurite outgrowth. We used an antibody specific for phosphorylated threonines $37 / 46$, a site those phosphorylation is required for the inactivation of $4 \mathrm{E}-\mathrm{BP} 1$ and its dissociation from the elF4E complex ${ }^{[28]}$. Incubation of the cultured cortical neurons with atorvastatin $(10 \mu \mathrm{mol} / \mathrm{L})$ for $48 \mathrm{~h}$ increased the phosphorylation of 4E-BP1. Furthermore, atorvastatininduced increases in the phosphorylation of $4 \mathrm{E}-\mathrm{BP} 1$ was completely blocked by LY294002 $(30 \mu \mathrm{mol} / \mathrm{L})$ and rapamycin 
A
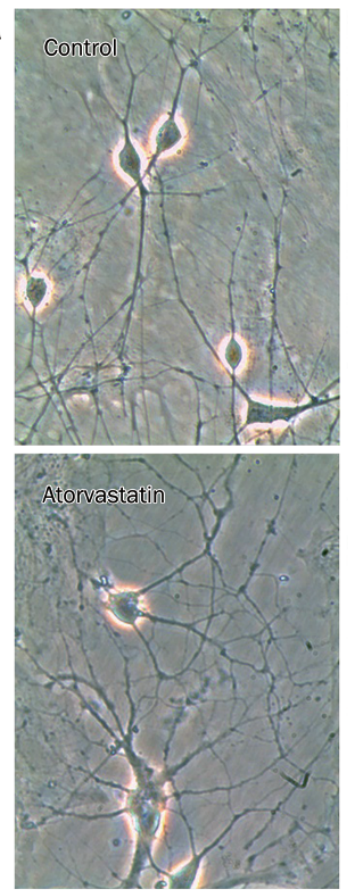
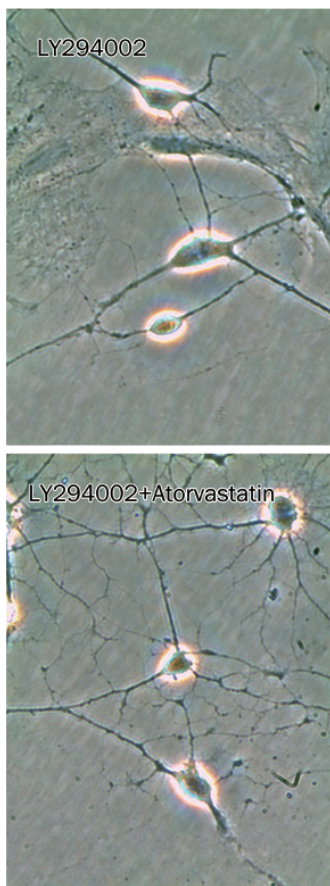
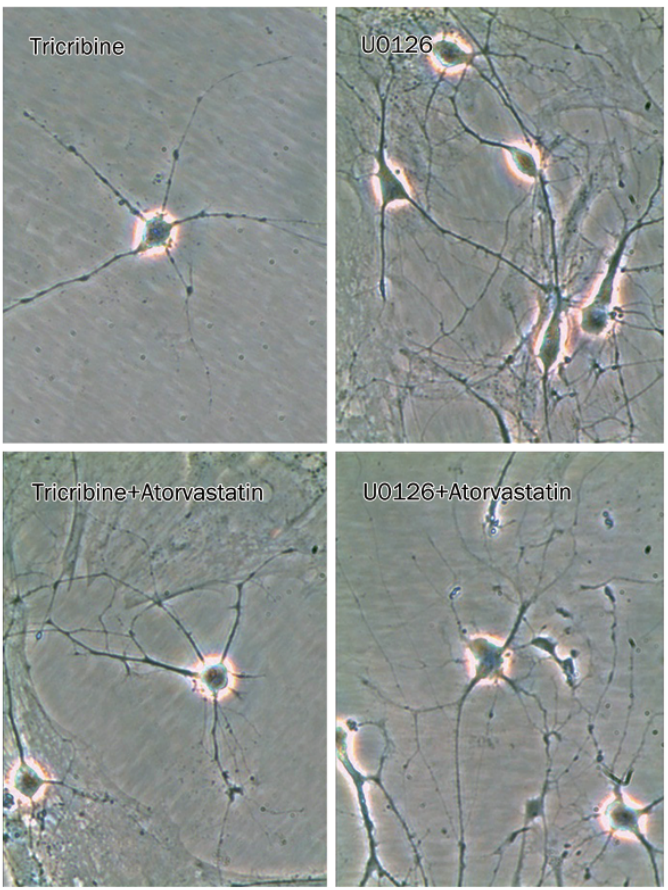

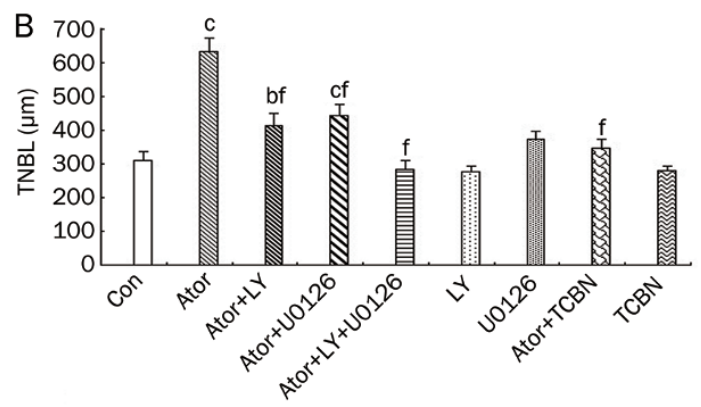

C
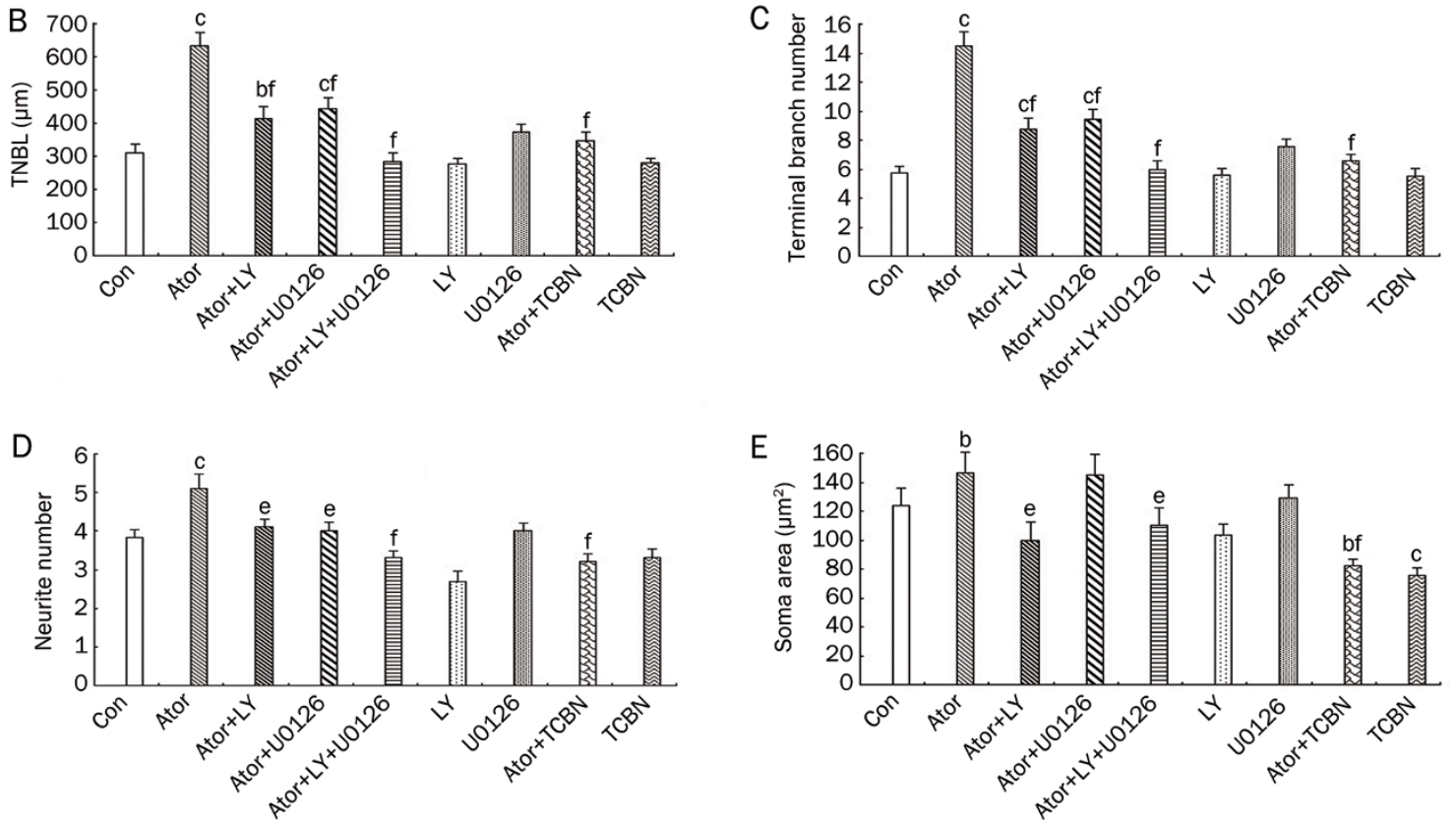

Figure 3. Atorvastatin (Ator) increases neurite outgrowth and soma size through PI3K/Akt and MAPK pathways. (A) Cultured neurons at 4 DIV were pretreated with vehicle, LY294002 (LY, $30 \mu \mathrm{mol} / \mathrm{L})$, U0126 $(10 \mu \mathrm{mol} / \mathrm{L})$, or tricribine (TCBN, $1 \mu \mathrm{mol} / \mathrm{L})$ for 30 min and then exposed to atorvastatin $(10 \mu \mathrm{mol} / \mathrm{L})$ for $48 \mathrm{~h}$ in the presence of vehicle or inhibitor. Following the treatment period, phase-contrast digital images of the cells were taken using a phase-contrast microscope. The graphs show mean \pm SEM for TNBL (B), terminal branch number (C), neurite number (D), and soma area (E). Quantifications were performed from at least three independent experiments ( $n=50-60$ neurons). ${ }^{\mathrm{b}} P<0.05,{ }^{\mathrm{C}} P<0.01$ compared with control group; ${ }^{\mathrm{e}} \mathrm{P}<0.05,{ }^{\mathrm{f}} \mathrm{P}<0.01$ compared with $10 \mu \mathrm{mol} / \mathrm{L}$ atorvastatin group.

(100 nmol/L) pretreatment, respectively (Figure 6B). These results support the suggestion that activation of both p70S6K and 4E-BP1 are required for atorvastatin-induced neurite outgrowth. 
A Atorvastatin
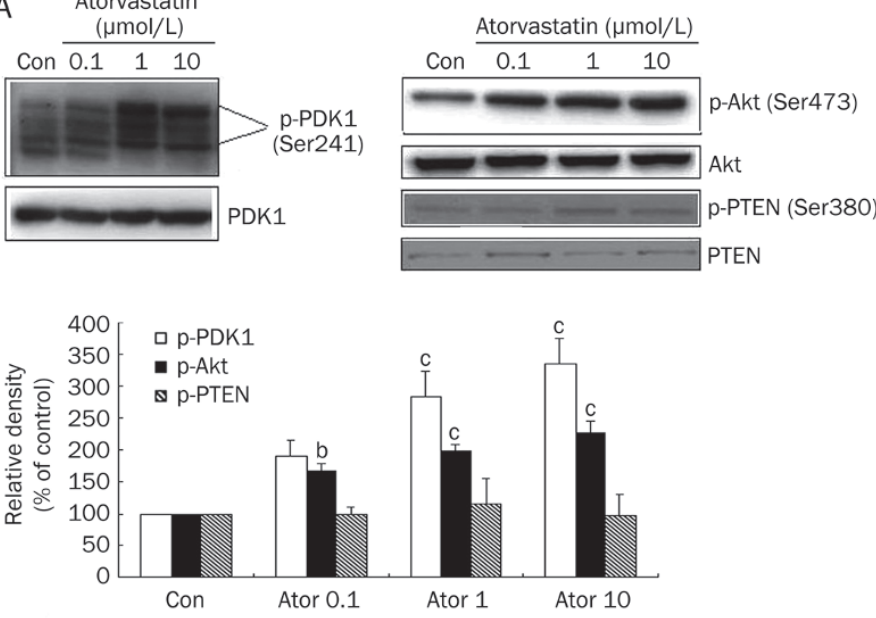

c
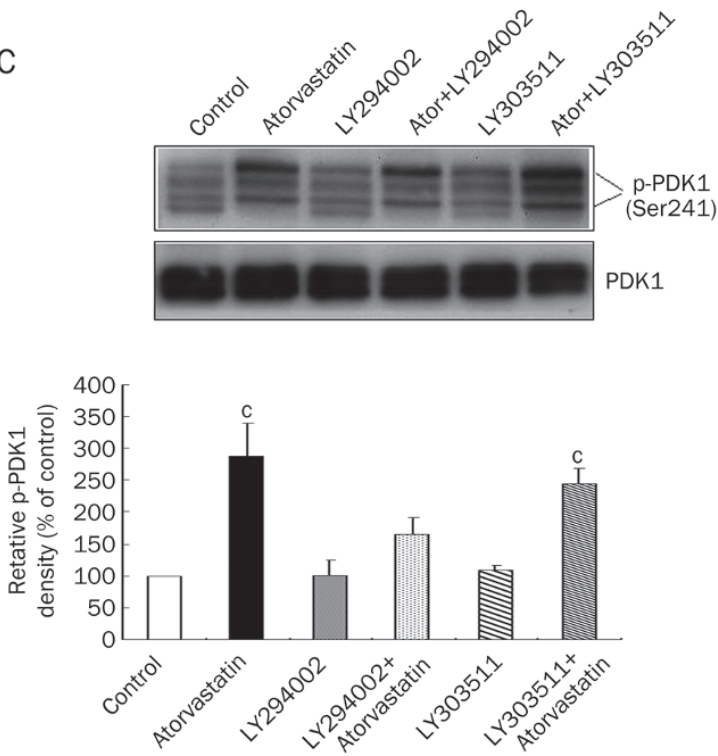

B
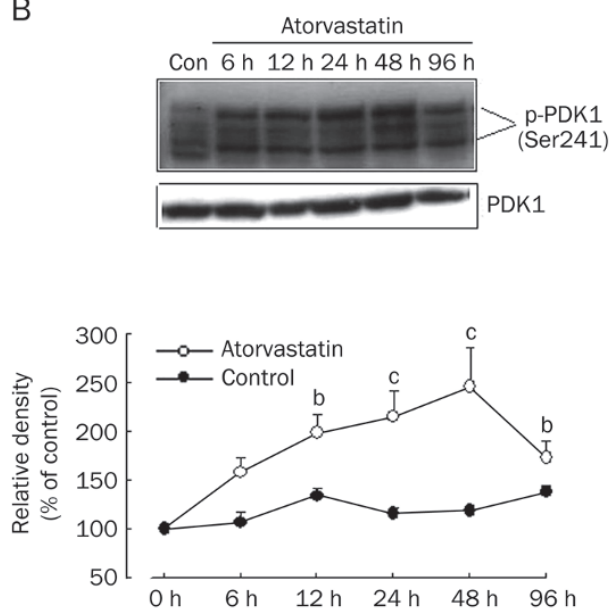

D
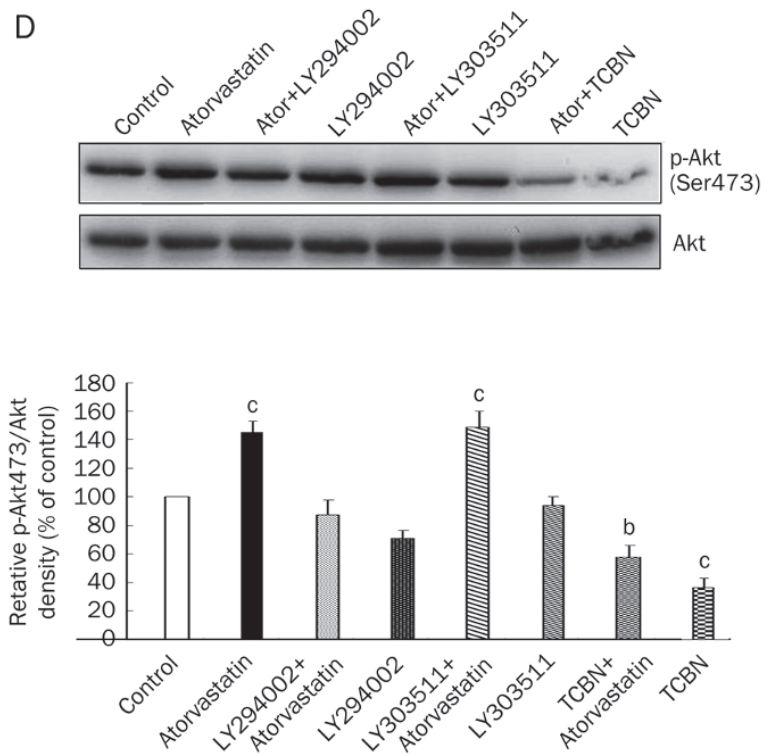

Figure 4. (A) Representative Western blot showing that atorvastatin induced increases in phosphorylation of PDK1 and Akt in a concentrationdependent manner, whereas atorvastatin did not have significant effects on phospho-PTEN. Group data showing the normalization of phospho-PDK1, phospho-Akt, and phospho-PTEN proteins to total PDK1, Akt, and proteins was determined in each group of four experiments. (B) Representative Western blot showing the level of phospho-PDK1 taken at different times after adding atorvastatin ( $10 \mu m o l / L)$. Group data showing the normalization of phospho-PDK1 proteins to total PDK1 protein was determined in each group of four experiments. (C) Representative Western blot showing that LY294002 inhibited atorvastatin-induced increases in phosphorylation of PDK1, whereas LY303511 did not have an effect. Group data showing the normalization of phospho-PDK1 to total PDK1 protein was determined in each group of four experiments. (D) Representative Western blot showing that both LY294002 and tricribine inhibited atorvastatin-induced increases in phosphorylation of Akt (Ser473). Group data showing normalization of phosphorylated Akt to total kinase was determined in each group of four experiments. Mean \pm SEM. ${ }^{b} P<0.05,{ }^{c} P<0.01$ compared with control group.

Atorvastatin increases neurite outgrowth through the Akt/GSK3 $\beta$ pathway

Signaling via the Akt/GSK-3 $\beta$ pathway can regulate neurite morphology by regulating phosphorylation of MAP2 ${ }^{[17]}$. Akt phosphorylates GSK-3 $\beta$ to inactivate it. Inactivation of GSK-3 $\beta$ leads to decreased phosphorylation of MAP2 and its increased binding and stabilization of microtubules. To test whether GSK-3 $\beta$ mediates the effects of atorvastatin on neurite outgrowth, we treated cultured cortical neurons with SB415286, a specific GSK-3 $\beta$ inhibitor. GSK-3 $\beta$ inhibition by
SB415286 (5 $\mu \mathrm{mol} / \mathrm{L})$ caused an increase in TNBL, terminal branch number, neurite number, and soma area. Treatment of neurons with a combination of atorvastatin $(10 \mu \mathrm{mol} / \mathrm{L})$ and SB415286 $(5 \mu \mathrm{mol} / \mathrm{L})$ caused an additive effect on TNBL, neurite number, terminal branch number, and soma area (Figure 7A-7E). To further test whether atorvastatin can promote neurite growth by regulating the Akt/GSK-3 $\beta$ pathway in cultured cortical neurons, we tested for phosphorylation of GSK-3 $\beta$ in cells treated with atorvastatin. Phosphorylation of GSK-3 $\beta$ increased in response to treatment with atorvastatin 
A
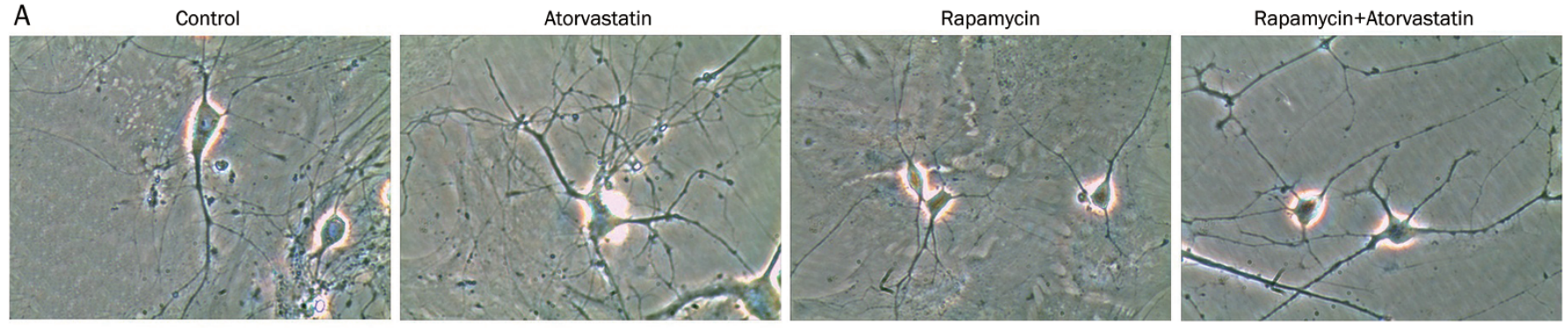

C
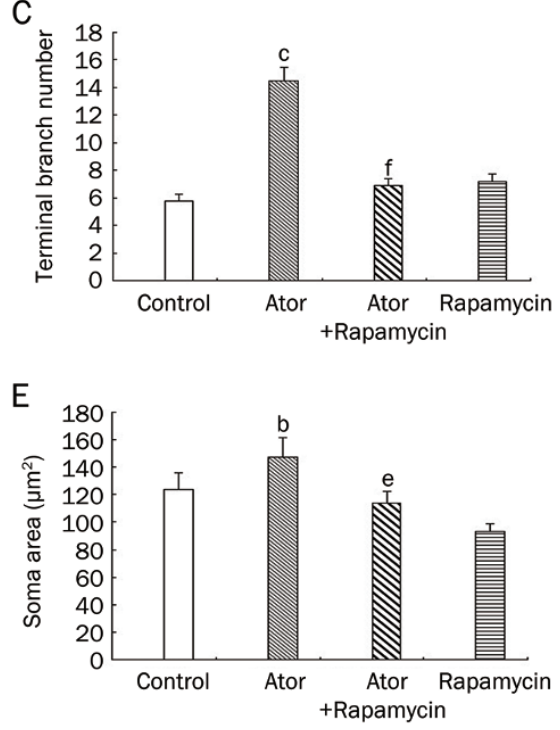

F

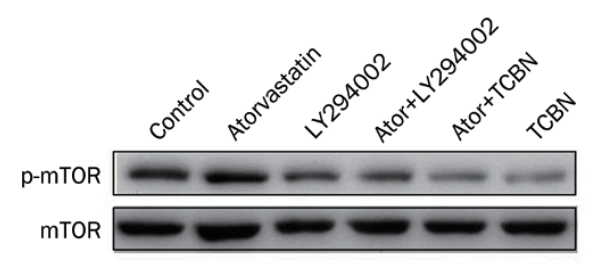

D

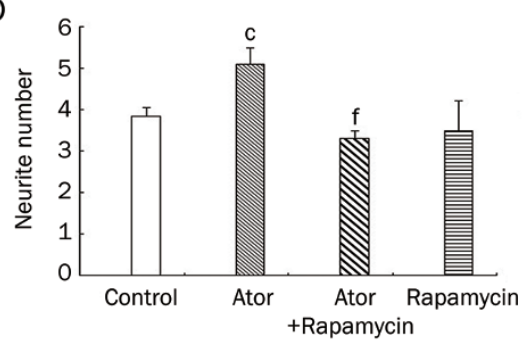

B

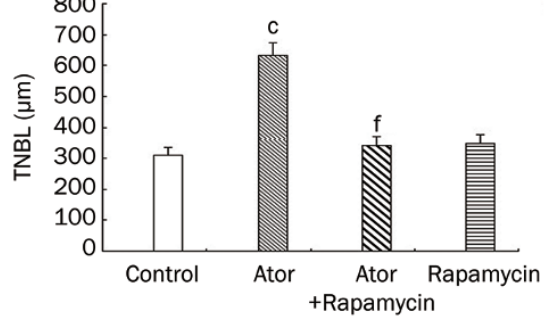

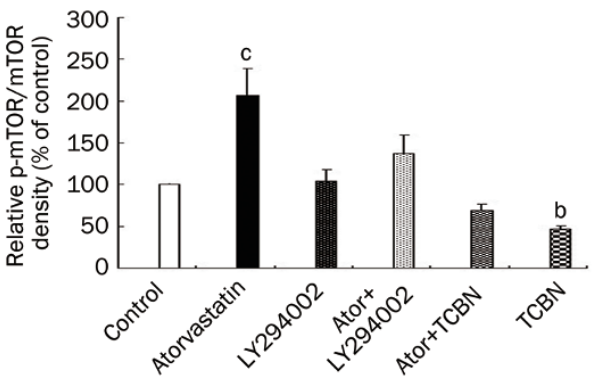

Figure 5. Atorvastatin enhances neurite outgrowth as well as soma size in an mTOR-dependent manner. (A) Cultured neurons at 4 DIV were pretreated with vehicle, rapamycin $(100 \mathrm{nmol} / \mathrm{L})$ for $30 \mathrm{~min}$ and then exposed to atorvastatin $(10 \mu \mathrm{mol} / \mathrm{L})$ for $48 \mathrm{~h}$ in the presence of vehicle or inhibitor. Following the treatment period, phase-contrast digital images of the cells were taken using a phase-contrast microscope. The graphs show mean \pm SEM for TNBL $(B)$, terminal branch number $(C)$, neurite number $(D)$, and soma area $(E)$. Quantifications were performed from at least three independent experiments ( $n=50-60$ neurons in each experiment). ${ }^{\mathrm{b}} P<0.05,{ }^{\mathrm{C}} P<0.01$ compared with control group; ${ }^{\mathrm{e}} P<0.05,{ }^{\mathrm{f}} P<0.01$ compared with $10 \mu \mathrm{mol} / \mathrm{L}$ atorvastatin group. (F) Representative Western blot showing both LY294002 and tricribine inhibited atorvastatin-induced increases in phosphorylation of mTOR (Ser2448). Group data showing normalization of phosphorylated mTOR to total kinase was determined in each group of four experiments. Mean \pm SEM. ${ }^{\mathrm{b}} P<0.05,{ }^{\mathrm{c}} P<0.01$ compared with control group.

$(10 \mu \mathrm{mol} / \mathrm{L})$ (Figure 7F). To confirm that GSK-3 $\beta$ mediates the effect of atorvastatin on neurite outgrowth, we treated cultured cortical neurons with either LY294002 or tricribine. Pretreatment with LY294002 (30 $\mu \mathrm{mol} / \mathrm{L})$ or tricribine $(1 \mu \mathrm{mol} / \mathrm{L})$ before adding atorvastatin completely blocked atorvastatininduced phosphorylation of GSK-3 $\beta$ (Figure 7F). These treatments did not affect GSK- $3 \beta$ protein levels. Together, these results suggest that atorvastatin enhances neurite outgrowth through the Akt/GSK-3 $\beta$ pathway.

\section{Discussion}

This study demonstrates that atorvastatin promotes neurite outgrowth by activating the PI3K/Akt/mTOR and Akt/ GSK-3 $\beta$ signal pathways in cultured cortical neurons. Our findings are consistent with previous reports that statins significantly induce neurite outgrowth in cultured hippocampal neurons ${ }^{[12]}$, explants of rat embryonic cortex and post-natal spinal cord ${ }^{[13]}$ and PC12 cells ${ }^{[11]}$. In contrast, statins have also been reported to inhibit neurite outgrowth in cultured cortical neurons, either by reducing cholesterol levels ${ }^{[29]}$ or by inhibition of isoprenylation ${ }^{[30]}$. However, these studies started statin treatment within $24 \mathrm{~h}$ of plating primary neuronal cells. In the present study, we grew the neurons in culture for $4 \mathrm{~d}$ before starting treatment to better understand the effect that statin treatment might have more developmentally mature neurons. A possible explanation for this discrepancy is increased sensitivity of immature neurons to toxicity induced by inhibition of mevalonate synthesis. Comparison of these results also suggests that statins may either stimulate or inhibit neuronal growth, depending on the stage of neuronal development. How can enhancement of neurite outgrowth by atorvastatin be explained? Our results are summarized in Figure 8, which 
A
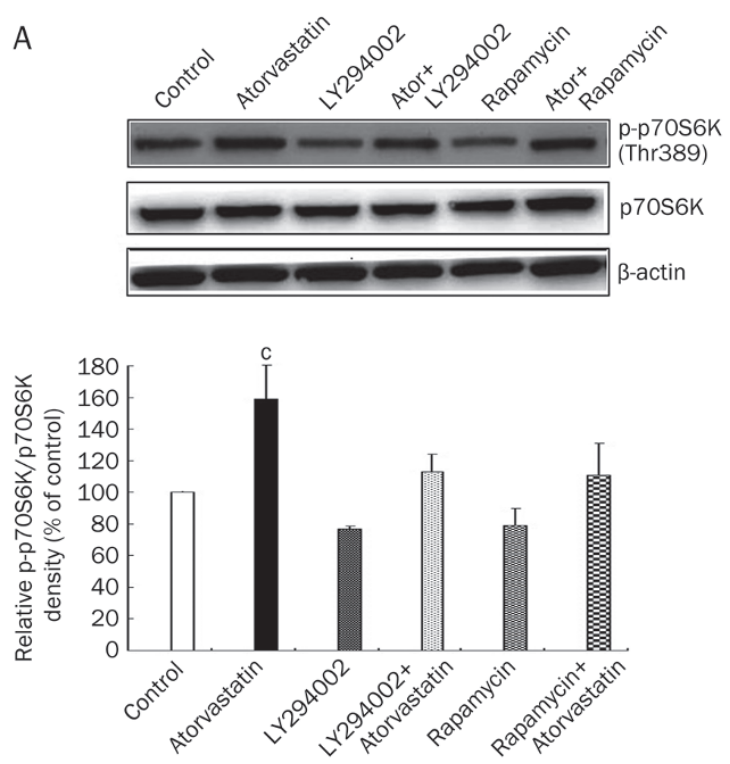

B
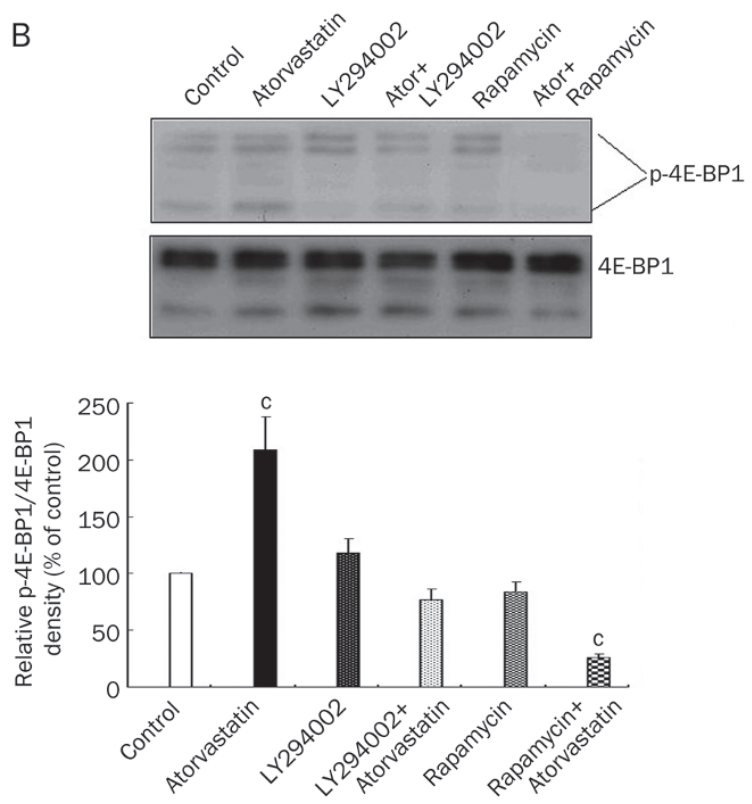

Figure 6. Atorvastatin-induced increases in the phosphorylation of p70S6K and 4E-BP1 are PI3K- and mTOR-dependent. Cultured cortical neurons at 4 DIV were pretreated with vehicle, LY294002 (30 $\mu \mathrm{mol} / \mathrm{L})$ or rapamycin $(100 \mathrm{nmol} / \mathrm{L})$ for $30 \mathrm{~min}$ and then exposed to atorvastatin $(10 \mu \mathrm{mol} / \mathrm{L})$ for $48 \mathrm{~h}$ in the presence of vehicle or inhibitor. (A) Representative Western blot showing both LY294002 and rapamycin inhibited atorvastatin-induced increases in phosphorylation of $\mathrm{p} 70 \mathrm{~S} 6 \mathrm{~K}$ (Thr389). Group data showing normalization of phosphorylated p70s6K to total kinase was determined in each group of four experiments. (B) Representative Western blot showing both LY294002 and rapamycin inhibited atorvastatin-induced increases in phosphorylation of $4 \mathrm{E}$ BP1 (Thr70). Group data showing normalization of phosphorylated 4EBP1 to total kinase was determined in each group of four experiments. Mean \pm SEM. ${ }^{c} P<0.01$ compared with control group.

will serve as a guide to the discussion. A previous report has demonstrated that pravastatin's stimulation of neurite out- growth is mediated by reduction of RhoA signaling via inhibition of geranylgeranylation ${ }^{[12]}$. In addition to the Rho family proteins $^{[31]}$, Akt has been revealed as a key mediator of several aspects of neurite outgrowth, including elongation, branching and caliber ${ }^{[15]}$. Several in vitro and in vivo studies provided evidence that statins activate the PKB/Akt pathway ${ }^{[3,32,33]}$. Though the mechanism of Akt activation by statins is not known, a study on mammalian endothelial cells demonstrated that simvastatin activates Akt in these cells, while treatment with wortmannin or LY294002 blocked this activation of Akt, suggesting that PI3-kinase signaling is involved ${ }^{[33]}$. Our study is the first demonstration to our knowledge that the PI3K/Akt pathway is involved in enhancement of neurite outgrowth by atorvastatin because this process was blocked by wortmannin or LY294002. Furthermore, Western blotting reveals that atorvastatin increased PDK1 and Akt phosphorylation. Therefore, activation of Akt by atorvastatin as demonstrated here is one explanation for the effect of the drug on neurite outgrowth in cortical neurons. The question remains of how atorvastatin activates specific protein kinase such as Akt. The involvement of Ras in the activation of PI3K has been reported ${ }^{[34]}$. It has been reported that lovastatin stimulates rapid activation of Ras, which associates with and activates PI3K in the plasma membrane, which in turn regulates $\mathrm{Akt}^{[35]}$. Based on these previous reports, we propose the hypothesis that atorvastatin activates Akt through activation of Ras and further facilitates neurite outgrowth in cortical neurons. We need to further clarify the specific downstream signal of Akt that promotes neurite outgrowth in the presence of atorvastatin.

Akt phosphorylates or interacts with a number of proteins that may positively influence the development of neuronal morphology. The PI3K/Akt pathway is known to regulate the mTOR pathway, and mTOR has been shown to be a direct substrate of Akt. PI3K/Akt/mTOR signaling has been shown to promote growth and branching in hippocampal neurons ${ }^{[16]}$. In recent reports, mTOR promoted axonal regeneration in the adult central nervous system and increased the axonal growth of injured peripheral nerves ${ }^{[36,37]}$. In our experiment, atorvastatin increased the activation of mTOR and p70S6K while rapamycin, an inhibitor of mTOR, decreased the effect of atorvastatin on neurite outgrowth. These results implicated mTOR as a signal of neurite outgrowth in neurons stimulated by atorvastatin. Akt is the main upstream regulator of mTOR in many cellular functions ${ }^{[38]}$, and in our experiments the inhibition of PI3K-dependent Akt activation by LY294002 decreased the activation of mTOR. In addition, both LY294002 and Akt inhibitor blocked neurite outgrowth facilitated by atorvastatin. Based on these results, we believe that atorvastatin increases the phosphorylation of mTOR and neurite outgrowth through PI3K and Akt. The PI3K pathway to mTOR is mediated by Akt and results in inhibition of tuberin, a GAP (GTPase-activating protein) for Rheb (Ras homolog enriched in brain); elevated GTP-bound Rheb then stimulates $\mathrm{mTOR}^{[39-41]}$. In addition, atorvastatin may activate the mTORC2 complex, thereby stimulating phosphorylation of Akt at Ser473 ${ }^{[2,43]}$. mTOR activation stimulated transla- 

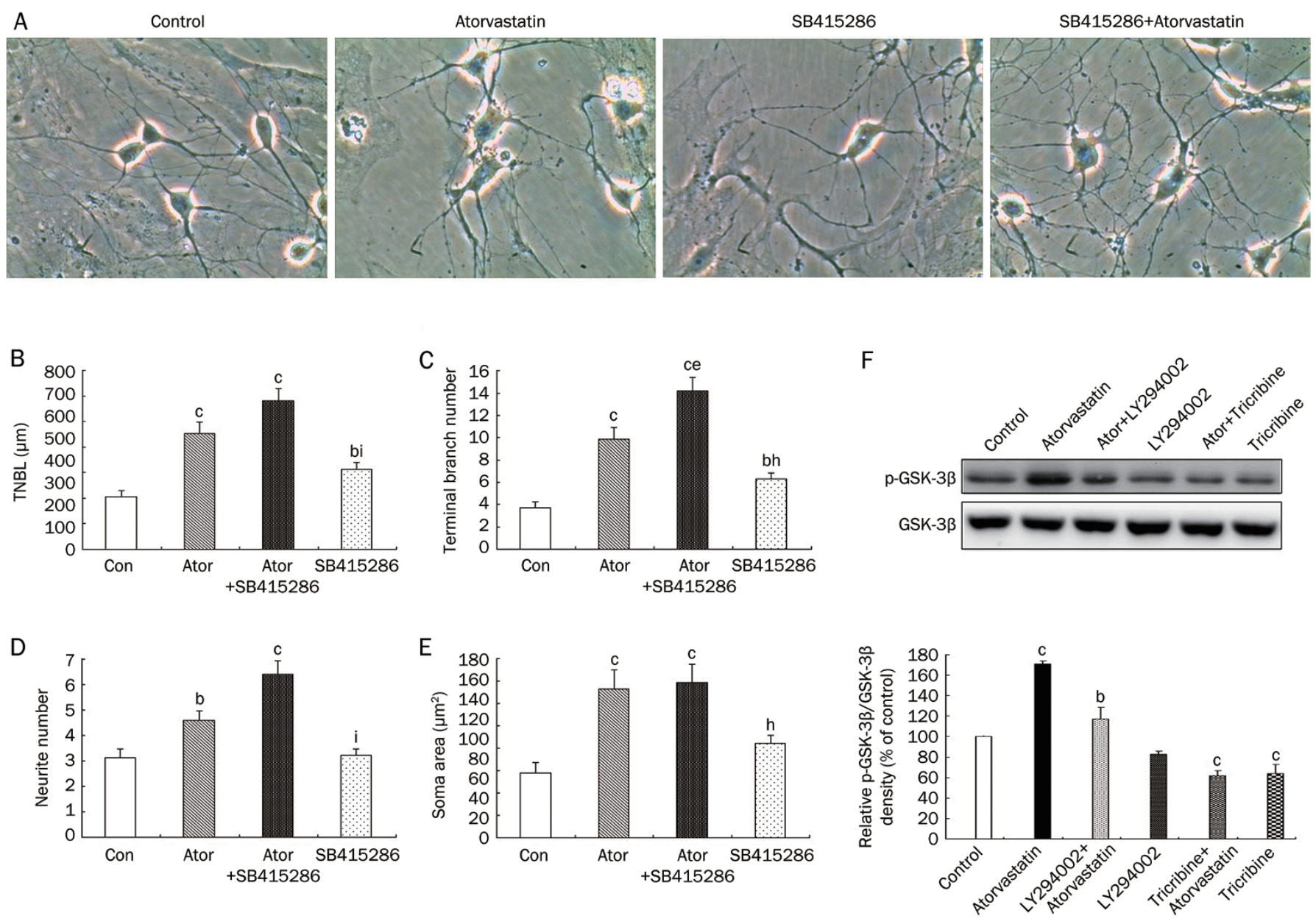

Figure 7. Atorvastatin enhances neurite outgrowth through the PI3K/Akt/GSK-3ß pathway. (A) Cultured neurons at 4 DIV were pretreated with vehicle or SB415286 $(5 \mu \mathrm{mol} / \mathrm{L})$ for $30 \mathrm{~min}$ and then exposed to atorvastatin $(10 \mu \mathrm{mol} / \mathrm{L})$ for $48 \mathrm{~h}$ in the presence of vehicle or inhibitor. Following the treatment period, phase-contrast digital images of the cells were taken using a phase-contrast microscope. The graphs show mean \pm SEM for TNBL $(B)$, terminal branch number $(C)$, neurite number $(D)$, and soma area $(E)$. Quantifications were performed from at least three independent experiments ( $n=50$-60 neurons). ${ }^{b} P<0.05,{ }^{\mathrm{C}} P<0.01$ compared with control group; ${ }^{\mathrm{e}} P<0.05$ compared with $10 \mu \mathrm{mol} / \mathrm{L}$ atorvastatin group. ${ }^{\mathrm{h}} P<0.05,{ }^{\mathrm{i}} P<0.01$ compared with atorvastatin+SB415286 group. (F) Representative Western blot showing both LY294002 and tricribine inhibited atorvastatin-induced increases in phosphorylation of GSK-3 $\beta$ (Ser9). Group data showing normalization of phosphorylated GSK-3 $\beta$ to total kinase was determined in each group of four experiments. Mean \pm SEM. ${ }^{b} P<0.05,{ }^{C} P<0.01$ compared with control group.

tional initiation involving both $4 \mathrm{E}-\mathrm{BP} 1$ and $\mathrm{p} 70 \mathrm{~S} 6 \mathrm{~K}^{[22]}$, which stimulate translation of $5^{\prime}$ capped and $5^{\prime} \mathrm{TOP}\left(5^{\prime}\right.$-terminal oligo pyrimidine tract) mRNAs, respectively ${ }^{[24,44]}$. mTOR and its substrates 4E-BP1 and p70S6Ks are present in dendrites ${ }^{[45]}$. p70S6Ks requires hierarchical phosphorylation by mTOR and MAPK for optimal activation ${ }^{[46]}$. Similarly, 4 E-BP1 is also phosphorylated by mTOR and MAPK at multiple sites ${ }^{[47]}$. These might be partially accountable for the involvement of both PI3K and MAPK in neurite formation. The phosphorylated $4 \mathrm{E}-\mathrm{BP} 1$ is replaced by eIF4G, a scaffolding translation factor that assembles several critical components of the capdependent translation initiation complex on the mRNA via its interaction with cap-bound eIF4E ${ }^{[48]}$. The activated p70S6K then phosphorylates ribosomal protein $\mathrm{S6}$, which can result in enhanced translation of $5^{\prime}$-oligopyrimidine tract-containing mRNAs that encode numerous components of translation machinery ${ }^{[48]}$. In our study, atorvastatin treatment leads to increased phosphorylation of 4E-BP1 and p70S6K, both of which are inhibited by rapamycin. Thus, activation of mTOR by atorvastatin may enhance both cap-dependent translation (eIF4E pathway) and initiation of 5'-oligopyrimidine tract-containing mRNAs (p70S6K-ribosomal protein S6 pathway). It has been shown that suppression of p70S6K or overexpression of 4E-BP1 impairs dendrite branching similarly to inhibition of $\mathrm{mTOR}^{[16]}$. Additional investigation into the potential role of p70S6K and 4E-BP1 in atorvastatin-induced neurite outgrowth would be of great interest.

Activated Akt phosphorylates GSK-3 $\beta$ at Ser9 to inactivate its kinase activity ${ }^{[17]}$; thus, GSK-3 $\beta$ activity is inversely correlated with PI3K/Akt signaling activity ${ }^{[49]}$. Some studies have observed GSK-3 $\beta$ phosphorylation following Akt activation and subsequently neurite outgrowth ${ }^{[50,51]}$. Our study 


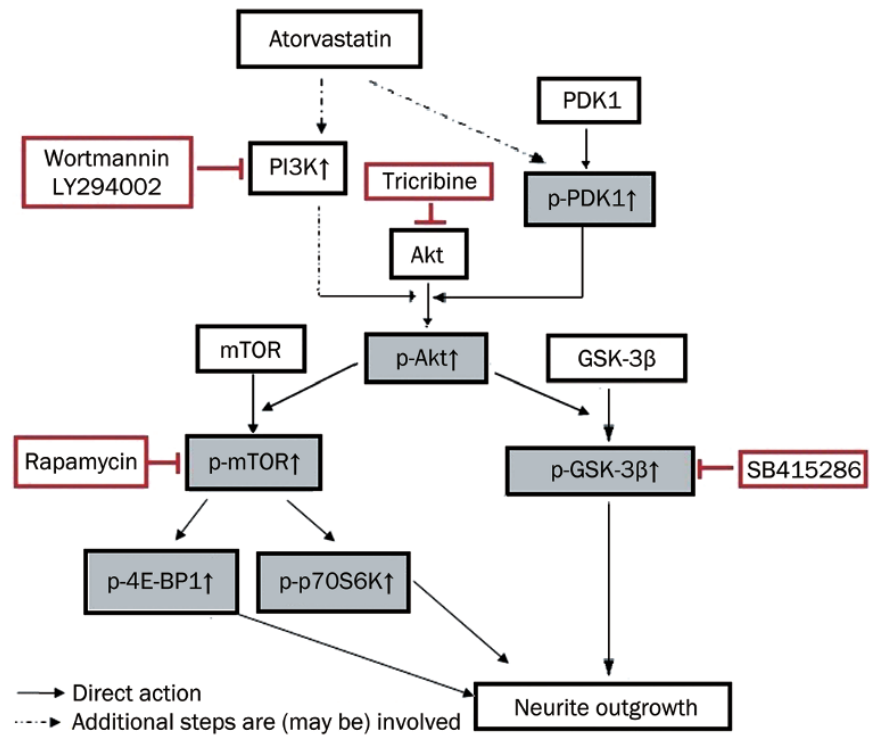

Figure 8. Schematic view of the effects of atorvastatin on PI3K pathways. Findings based on the present study are in bold and highlighted by shaded boxes. The inhibitors used in the study are boxed in red.

demonstrates that treatment of cultured cortical neurons with atorvastatin increased phosphorylation of GSK-3 $\beta$ (Ser9). Inhibiting PI3K with LY294002 or directly inhibiting Akt with tricribine blocked the atorvastatin-induced increase in phosphorylated GSK-3 $\beta$ (Ser9). Another study also demonstrates that simvastatin increases phosphorylation of GSK-3 $\beta$ (Ser9) in the hippocampus in rats after traumatic brain injury ${ }^{[3]}$. GSK-3 $\beta$, which is inactivated upon phosphorylation by Akt, is implicated in the regulation of microtubule dynamics by phosphorylating MAPs, including adenomatosis polyposis coli (APC), MAP1, and MAP2 ${ }^{[52]}$. Phosphorylation of MAPs is a key step in the regulatation of neurite initiation, growth, and branching in hippocampal neurons ${ }^{[17]}$. Decreased activity of GSK-3 $\beta$ reduces phosphorylation of MAP2, a step that can enhance microtubule polymerization and dendritic growth ${ }^{[53]}$.

Taken together, we have shown for the first time that atorvastatin can regulate neurite outgrowth via the PI3K/Akt/ mTOR and PI3K/Akt/GSK-3 $\beta$ pathways in cultured cortical neurons. It will be important to investigate the effects of atorvastatin on neurite growth in vivo. We believe that statins have great potential for treating several nervous disorders. Our results indicate a novel cholesterol-independent effect of statins and call for further studies to reveal the responsible mechanisms.

\section{Acknowledgements}

This work was supported by grant from Education Commission of Liaoning Province (LT2010064).

\section{Author contribution}

Ying JIN designed the research; Hai-juan SUI, Yan DONG, Qi DING, Wen-hui QU, Sheng-xue YU, and Ying-xin JIN performed the research; Hai-juan SUI and Wen-hui QU analyzed the data; and Ying JIN wrote the paper.

\section{References}

1 Asahi M, Huang Z, Thomas S, Yoshimura S, Sumii T, Mori T, et al. Protective effects of statins involving both eNOS and tPA in focal cerebral ischemia. J Cereb Blood Flow Metab 2005; 25: 722-9.

2 Bosel J, Gandor F, Harms C, Synowitz M, Harms U, Djoufack PC, et al. Neuroprotective effects of atorvastatin against glutamate-induced excitotoxicity in primary cortical neurones. J Neurochem 2005; 92: 1386-98.

3 Wu H, Lu D, Jiang H, Xiong Y, Qu C, Li B, et al. Simvastatin-mediated upregulation of VEGF and BDNF, activation of the PI3K/Akt pathway, and increase of neurogenesis are associated with therapeutic improvement after traumatic brain injury. J Neurotrauma 2008; 25: 130-9.

4 Mahmood A, Goussev A, Kazmi H, Qu C, Lu D, Chopp M. Long-term benefits after treatment of traumatic brain injury with simvastatin in rats. Neurosurgery 2009; 65: 187-91.

5 Han X, Yang N, Xu Y, Zhu J, Chen Z, Liu Z, et al. Simvastatin treatment improves functional recovery after experimental spinal cord injury by upregulating the expression of BDNF and GDNF. Neurosci Lett 2011; 487: 255-9.

6 Fonseca AC, Resende R, Oliveira CR, Pereira CM. Cholesterol and statins in Alzheimer's disease: current controversies. Exp Neurol 2010; 223: 282-93.

7 Fassbender K, Simons M, Bergmann C, Stroick M, Lutjohann D, Keller $\mathrm{P}$, et al. Simvastatin strongly reduces levels of Alzheimer's disease beta -amyloid peptides Abeta 42 and Abeta 40 in vitro and in vivo. Proc Natl Acad Sci U S A 2001; 98: 5856-61.

8 Pedrini S, Carter TL, Prendergast G, Petanceska S, Ehrlich ME, Gandy S. Modulation of statin-activated shedding of Alzheimer APP ectodomain by ROCK. PLoS Med 2005; 2: e18.

9 Gellermann GP, Ullrich K, Tannert A, Unger C, Habicht G, Sauter SR, et al. Alzheimer-like plaque formation by human macrophages is reduced by fibrillation inhibitors and lovastatin. J Mol Biol 2006; 360: 251-7.

10 Won JS, Im YB, Khan M, Contreras M, Singh AK, Singh I. Lovastatin inhibits amyloid precursor protein (APP) beta-cleavage through reduction of APP distribution in Lubrol WX extractable low density lipid rafts. J Neurochem 2008; 105: 1536-49.

11 Fernandez-Hernando C, Suarez Y, Lasuncion MA. Lovastatin-induced PC-12 cell differentiation is associated with RhoA/RhoA kinase pathway inactivation. Mol Cell Neurosci 2005; 29: 591-602.

12 Pooler AM, Xi SC, Wurtman RJ. The 3-hydroxy-3-methylglutaryl coenzyme A reductase inhibitor pravastatin enhances neurite outgrowth in hippocampal neurons. J Neurochem 2006; 97: 716-23.

13 Holmberg E, Nordstrom T, Gross M, Kluge B, Zhang SX, Doolen S. Simvastatin promotes neurite outgrowth in the presence of inhibitory molecules found in central nervous system injury. J Neurotrauma 2006; 23: 1366-78.

14 Evangelopoulos ME, Weis J, Kruttgen A. Mevastatin-induced neurite outgrowth of neuroblastoma cells via activation of EGFR. J Neurosci Res 2009; 87: 2138-44.

15 Read DE, Gorman AM. Involvement of Akt in neurite outgrowth. Cell Mol Life Sci 2009; 66: 2975-84.

16 Chen J, Zhang ZG, Li Y, Wang Y, Wang L, Jiang H, et al. Statins induce angiogenesis, neurogenesis, and synaptogenesis after stroke. Ann Neurol 2003; 53: 743-51.

17 Kretz A, Schmeer C, Tausch S, Isenmann S. Simvastatin promotes heat shock protein 27 expression and Akt activation in the rat retina and protects axotomized retinal ganglion cells in vivo. Neurobiol Dis 
2006; 21: 421-30.

18 Skaletz-Rorowski A, Lutchman M, Kureishi Y, Lefer DJ, Faust JR, Walsh K. HMG-CoA reductase inhibitors promote cholesterol-dependent Akt/PKB translocation to membrane domains in endothelial cells. Cardiovasc Res 2003; 57: 253-64.

19 Alessi DR, Andjelkovic M, Caudwell B, Cron P, Morrice N, Cohen P, et al. Mechanism of activation of protein kinase B by insulin and IGF-1. EMBO J 1996; 15: 6541-51.

20 Burnett PE, Barrow RK, Cohen NA, Snyder SH, Sabatini DM. RAFT1 phosphorylation of the translational regulators p70 S6 kinase and 4EBP1. Proc Natl Acad Sci U S A 1998; 95: 1432-7.

21 Brunn GJ, Fadden P, Haystead TA, Lawrence JC Jr. The mammalian target of rapamycin phosphorylates sites having a (Ser/Thr)-Pro motif and is activated by antibodies to a region near its $\mathrm{COOH}$ terminus. J Biol Chem 1997; 272: 32547-50.

22 Jefferies HB, Fumagalli S, Dennis PB, Reinhard C, Pearson RB, Thomas G. Rapamycin suppresses 5'TOP mRNA translation through inhibition of p70s6k. EMBO J 1997; 16: 3693-704.

23 Scott PH, Brunn GJ, Kohn AD, Roth RA, Lawrence JC Jr. Evidence of insulin-stimulated phosphorylation and activation of the mammalian target of rapamycin mediated by a protein kinase B signaling pathway. Proc Natl Acad Sci U S A 1998; 95: 7772-7.

24 Jaworski J, Spangler S, Seeburg DP, Hoogenraad CC, Sheng M. Control of dendritic arborization by the phosphoinositide-3'-kinaseAkt-mammalian target of rapamycin pathway. J Neurosci 2005; 25 : 11300-12.

25 Kumar V, Zhang MX, Swank MW, Kunz J, Wu GY. Regulation of dendritic morphogenesis by Ras-PI3K-Akt-mTOR and Ras-MAPK signaling pathways. J Neurosci 2005; 25: 11288-99.

26 Dufner A, Thomas G. Ribosomal S6 kinase signaling and the control of translation. Exp Cell Res 1999; 253: 100-9.

27 Gingras AC, Raught B, Gygi SP, Niedzwiecka A, Miron M, Burley SK, et al. Hierarchical phosphorylation of the translation inhibitor 4E-BP1. Genes Dev 2001; 15: 2852-64.

28 Grimes CA, Jope RS. The multifaceted roles of glycogen synthase kinase 3beta in cellular signaling. Prog Neurobiol 2001; 65: 391426.

29 Fan QW, Yu W, Gong JS, Zou K, Sawamura N, Senda T, et al. Cholesterol-dependent modulation of dendrite outgrowth and microtubule stability in cultured neurons. J Neurochem 2002; 80: 178-90.

30 Schulz JG, Bosel J, Stoeckel M, Megow D, Dirnagl U, Endres M. HMGCoA reductase inhibition causes neurite loss by interfering with geranylgeranylpyrophosphate synthesis. J Neurochem 2004; 89: 24-32.

31 Van Aelst L, Cline HT. Rho GTPases and activity-dependent dendrite development. Curr Opin Neurobiol 2004; 14: 297-304.

32 Dimmeler S, Aicher A, Vasa M, Mildner-Rihm C, Adler K, Tiemann M, et al. HMG-CoA reductase inhibitors (statins) increase endothelial progenitor cells via the PI3-kinase/Akt pathway. J Clin Invest 2001; 108: 391-7.

33 Kureishi Y, Luo Z, Shiojima I, Bialik A, Fulton D, Lefer DJ, et al. The HMG-CoA reductase inhibitor simvastatin activates the protein kinase Akt and promotes angiogenesis in normocholesterolemic animals. Nat Med 2000; 6: 1004-10.

34 Rodriguez-Viciana P, Warne PH, Dhand R, Vanhaesebroeck B, Gout I, Fry MJ, et al. Phosphatidylinositol-3-OH kinase as a direct target of Ras. Nature 1994; 370: 527-32.

35 Ghosh-Choudhury N, Mandal CC, Choudhury GG. Statin-induced Ras activation integrates the phosphatidylinositol 3-kinase signal to Akt and MAPK for bone morphogenetic protein-2 expression in osteoblast differentiation. J Biol Chem 2007; 282: 4983-93.

36 Park KK, Liu K, Hu Y, Smith PD, Wang C, Cai B, et al. Promoting axon regeneration in the adult CNS by modulation of the PTEN/mTOR pathway. Science 2008; 322: 963-6.

37 Abe N, Borson SH, Gambello MJ, Wang F, Cavalli V. Mammalian target of rapamycin (mTOR) activation increases axonal growth capacity of injured peripheral nerves. J Biol Chem 2010; 285: 28034-43.

38 Jaworski J, Sheng $M$. The growing role of mTOR in neuronal development and plasticity. Mol Neurobiol 2006; 34: 205-19.

39 Manning BD, Tee AR, Logsdon MN, Blenis J, Cantley LC. Identification of the tuberous sclerosis complex-2 tumor suppressor gene product tuberin as a target of the phosphoinositide 3-kinase/akt pathway. Mol Cell 2002; 10: 151-62.

40 Garami A, Zwartkruis FJ, Nobukuni T, Joaquin M, Roccio M, Stocker $\mathrm{H}$, et al. Insulin activation of Rheb, a mediator of mTOR/S6K/4E-BP signaling, is inhibited by TSC1 and 2. Mol Cell 2003; 11: 1457-66.

41 Tee AR, Manning BD, Roux PP, Cantley LC, Blenis J. Tuberous sclerosis complex gene products, Tuberin and Hamartin, control mTOR signaling by acting as a GTPase-activating protein complex toward Rheb. Curr Biol 2003; 13: 1259-68.

42 Hresko RC, Mueckler M. mTOR.RICTOR is the Ser473 kinase for Akt/protein kinase B in 3T3-L1 adipocytes. J Biol Chem 2005; 280: 40406-16.

43 Sarbassov DD, Guertin DA, Ali SM, Sabatini DM. Phosphorylation and regulation of Akt/PKB by the rictor-mTOR complex. Science 2005; 307: 1098-101.

44 Beretta L, Gingras AC, Svitkin YV, Hall MN, Sonenberg N. Rapamycin blocks the phosphorylation of 4E-BP1 and inhibits cap-dependent initiation of translation. EMBO J 1996; 15: 658-64.

45 Tang SJ, Reis G, Kang H, Gingras AC, Sonenberg N, Schuman EM. $A$ rapamycin-sensitive signaling pathway contributes to long-term synaptic plasticity in the hippocampus. Proc Natl Acad Sci U S A 2002; 99: 467-72.

46 Schmelzle T, Hall MN. TOR, a central controller of cell growth. Cell 2000; 103: 253-62.

47 Herbert TP, Tee AR, Proud CG. The extracellular signal-regulated kinase pathway regulates the phosphorylation of 4E-BP1 at multiple sites. J Biol Chem 2002; 277: 11591-6.

48 Hay N, Sonenberg N. Upstream and downstream of mTOR. Genes Dev 2004; 18: 1926-45.

49 Cross DA, Alessi DR, Cohen P, Andjelkovich M, Hemmings BA. Inhibition of glycogen synthase kinase-3 by insulin mediated by protein kinase B. Nature 1995; 378: 785-9.

50 Kim Y, Seger R, Suresh Babu CV, Hwang SY, Yoo YS. A positive role of the PI3-K/Akt signaling pathway in PC12 cell differentiation. Mol Cells 2004; 18: 353-9.

51 Ooms LM, Fedele CG, Astle MV, Ivetac I, Cheung V, Pearson RB, et al. The inositol polyphosphate 5-phosphatase, PIPP, is a novel regulator of phosphoinositide 3-kinase-dependent neurite elongation. Mol Biol Cell 2006; 17: 607-22.

52 Segarra J, Balenci L, Drenth T, Maina F, Lamballe F. Combined signaling through ERK, PI3K/AKT, and RAC1/p38 is required for mettriggered cortical neuron migration. J Biol Chem 2006; 281: 4771-8.

53 Goold RG, Owen R, Gordon-Weeks PR. Glycogen synthase kinase 3beta phosphorylation of microtubule-associated protein $1 \mathrm{~B}$ regulates the stability of microtubules in growth cones. J Cell Sci 1999; 112: 3373-84. 